\title{
Post-traumatic stress, depression, and anxiety in patients with injury-related chronic pain: A pilot study
}

\author{
Sofia Åhman \\ Britt-Marie Stålnacke \\ Department of Community Medicine \\ and Rehabilitation, Umeå University, \\ Sweden
}

\begin{abstract}
Aim: To investigate, in patients with injury-related chronic pain, pain intensity, levels of post-traumatic stress, anxiety and depressions.

Methods: One hundred and sixty patients aged 17-62 years, admitted for assessment to the Pain Rehabilitation Clinic at the Umeå University Hospital, Umeå Sweden, for chronic pain caused by an injury, answered a set of questionnaires to assess post-traumatic stress (Impact of Event Scale [IES]), pain intensity (VAS), depression, and anxiety (Hospital Anxiety and Depression Scale [HAD]).

Results: Moderate to severe post-traumatic stress was reported by $48.1 \%$ of the patients. Possible-probable anxiety on the HAD was scored by $44.5 \%$ and possible-probable depression by $45.2 \%$. Pain intensity (VAS) was significantly correlated to post-traumatic stress $(r=0.183$, $\mathrm{p}=0.022)$, the HAD-scores anxiety $(\mathrm{r}=0.186, \mathrm{p}=0.0021)$, and depression $(\mathrm{r}=0.252, \mathrm{p}=0.002)$. No statistically significant differences were found between genders for post-traumatic stress, pain intensity, anxiety, or depression. Participants with moderate to severe stress reaction reported statistically significant higher anxiety scores on the HAD $(p=0.030)$ in comparison with patients with mild stress.
\end{abstract}

Conclusion: The findings of relationships between pain intensity, post-traumatic stress, depression, and anxiety may have implications for clinicians and underline the importance of considering all these factors when managing patients with injury-related chronic pain.

Keywords: post-traumatic stress disorder, anxiety, chronic pain

\section{Introduction}

Pain is one of the most common causes for seeking health care: $20 \%-40 \%$ of the patients treated by general practitioners are estimated to suffer from different pain conditions (Mantyselka et al 2001; Hasselstrom et al 2002). Pain is defined as "an unpleasant sensory and emotional experience associated with actual or potential tissue damage, or described in terms of such damage" (IASP 1986). Factors often associated with the development of long lasting pain include previous pain experiences, injuries, high age, female gender, and culture (Radanov et al 1995; Cote et al 2001; Kyhlback et al 2002). In western countries, an increase in chronic pain patients has paralleled an increase in costs. Swedish studies have shown that $40 \%-50 \%$ of the population is estimated to suffer from persistent pain and that the majority experience musculoskeletal pain. The country's total costs for chronic pain are estimated to 87.5 billion SEK (SCTA 2006). In this context, it is worth noticing that patients with chronic pain constitute a heterogeneous group with different backgrounds, personalities, and causes of pain that may influence the clinical characteristics (Borg et al 2006).

Traffic injuries and especially whiplash injuries are a common cause of long lasting pain. During the last decade, the incidence of these injuries seems to have increased and varies from 1.0 to 3.2/1000 and year (Barnsley et al 1994; Sterner et al 2003; 
Rodriquez et al 2004). The term whiplash describes a mechanism of energy caused by acceleration being transferred to the neck that results in soft tissue injury/distortion of the neck (Spitzer et al 1995). Although many patients with whiplash injuries recover within a few months after an accident, a significant proportion continues to suffer from a number of clinical long-lasting symptoms known as whiplash-associated disorder (WAD) (Spitzer et al 1995) with neck pain (Radanov et al 1995) and headache (Radanov et al 1995; Herrstrom et al 2000) as the dominating complaints. Patients may also suffer from symptoms such as posttraumatic stress, depression and anxiety, symptoms that can affect recovery (Andersson et al 1997; Bryant et al 1999). In a large cohort study, Carroll and colleagues (2006) examined the duration of depressive symptoms in whiplash patients. They found that patients frequently reported these symptoms in the acute phase and the symptoms often persisted one year after the injury.

Moreover, in several studies post-traumatic stress reactions have been shown after traffic accidents (Kuch et al 1996; Andersson et al 1997; Jaspers et al 1998; Taylor et al 2001) and a large proportion of chronic whiplash patients are expected to suffer from post-traumatic stress. The diagnosis of post-traumatic stress disorder has been reported in $10 \%-30 \%$ of patients injured in vehicle accidents. Although the severity of the post-traumatic stress complaints decreases with time, Mayou and colleagues (2001) have shown that about one-third of traffic victims still suffer from post-traumatic stress reactions with anxiety and avoidance behavior 4-6 years after the accident. These problems have been noticed by the Swedish Society of Medicine and the Whiplash Commission task force. This task force recently declared that post-traumatic stress symptoms should be diagnosed and treated early after a whiplash injury to minimize the risk for long-lasting symptoms (SSM 2005).

The Pain Rehabilitation Clinic at the University Hospital, Umeå, Sweden, provides multidisciplinary assessment and rehabilitation for patients with chronic pain.

Although validated questionnaires monitoring pain intensity, anxiety and depression are used routinely before the assessment, there is no systematic evaluation of posttraumatic stress. The aims of the present pilot-study were therefore to: (i) investigate the pain intensity, levels of post-traumatic stress, anxiety and depression in patients with injury-related chronic pain; (ii) to assess the relationships between these symptoms; (iii) to examine differences in post-traumatic stress, anxiety, depression and pain intensity between men and women and between patients with whiplash injuries and other causes to their trauma.

\section{Methods}

\section{Patients and procedures}

In total, 160 patients (103 women and 57 men, aged 17-62 years (36 \pm 10$)$ were admitted for assessment to the Pain Rehabilitation Clinic at the Umeå University Hospital, Umeå, Sweden, because of chronic pain caused by an injury between September 2005 and November 2007. Out of all the participants, $68 \%$ suffered from pain caused by whiplash injuries and $32 \%$ reported that their pain was caused by other accidents such as falls and assaults. The time between injury and assessment was $5.2 \pm 5.7$ years.

A set of questionnaires was sent to the participants before the assessment in the clinic. Information about the participants' trauma history was collected from hospital records.

\section{Instruments}

\section{The impact of event scale}

The Impact of Event Scale (IES) is a widely used selfreport scale (Horowitz et al 1979). It is a valid measure of post-traumatic stress reactions (Sundin and Horowitz 2002; Joseph 2003) and has been suggested as a screening tool for post-traumatic stress disorder (PTSD). The IES comprises 15 statements. Seven statements address intrusive symptoms and eight statements address avoidance symptoms. The patients answer the questionnaire regarding their symptoms during the previous week. A total score can vary from 0 to 80 and the score is divided into four grades or stress reactions: sub-clinical (0-8), mild (9-25), moderate (26-43) to severe (44-75) stress reactions (Kongstd et al 2007).

\section{Visual analogue scale}

The Visual Analogue Scale (VAS) (Scrimshaw and Maher 2001) was used to rate the pain intensity. The scale consists of a $100 \mathrm{~mm}$ straight line with defined end-points ("no pain" and "worst pain imaginable") on which the patients were asked to mark their experienced pain (results in $\mathrm{mm}$ ). The VAS is considered to have a high degree of reliability and validity (Wewers and Lowe 1990; Price et al 1994).

\section{HAD}

The Hospital Anxiety and Depression Scale (HAD) is an instrument for the measurements of anxiety and depression which is developed and validated on nonpsychiatric medical patients (Zigmond and Snaith 1983). The questionnaire comprises 14 items divided in two parts for rating of depression and anxiety. Each item has a four-response category range between 0 and 3 . The scale ranges between 0 and 21 for both depression and anxiety. According to Zigmond and 
Snaith (1983) the cut-off level for possible cases of anxiety disorder and depression is recommended at scores $\geq 8$ on each subscale.

\section{Statistical analysis}

All statistical analysis was performed with SPSS, (version 14.0 for Windows; SPSS Inc., Chicago, IL, USA). Data are reported as means \pm standard deviations unless indicated otherwise. Comparisons of populations were made using the Mann-Whitney U-test. Pearsons' correlation coefficient was calculated for the analysis of bivariate correlations. The statistical significant level was set at 0.05 .

The study was approved by the ethics committee of Umeå University.

\section{Results}

\section{Post-traumatic stress}

Moderate to severe stress response (total IES score of $\geq 26$ ) was reported by $48.1 \%$ of the participants, moderate stress response was reported by $38.1 \%$ and severe stress was reported by $10 \%$ (Figure 1). No statistically significant differences were found between genders with respect to total IES (women: $24 \pm 16$, men: $23 \pm 15$ ) and the subscales 'Intrusion' (women: $12 \pm 4$, men: $12 \pm 9$ ) and 'Avoidance' (women: $12 \pm 10$, men: $11 \pm 8, p>0.05$ ). The IES score in patients with whiplash injuries and patients with other causes to their trauma were compared and no statistically significant difference was shown $(\mathrm{p}>0.05)$.

\section{Anxiety and depression}

The frequency of patients who scored $\geq 8$ on the HAD (possible-probable depression/anxiety) was $44.5 \%$ for

\section{Post-traumatic stress reaction}

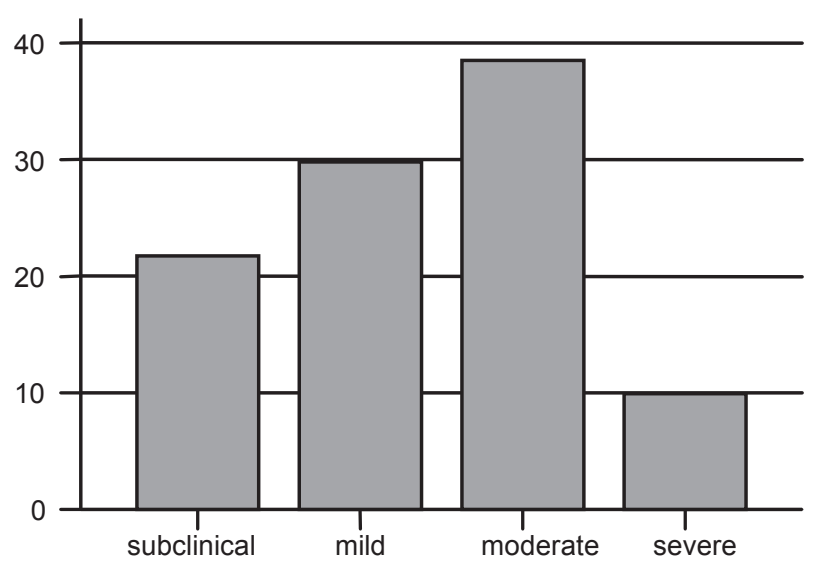

Figure I Percentage of participants within each stress reaction category. anxiety and $45.2 \%$ for depression. Anxiety scores on the HAD for all patients was $7.4 \pm 4.4$. Women rated slightly higher scores $(7.5 \pm 4.6)$ than men $(7.4 \pm 4.1)$, but the difference was not significant $(p>0.05)$. Depression scores on the HAD were $7.5 \pm 4.4$ for all participants, $7.3 \pm 4.4$ for women and $7.8 \pm 4.4$ for men. No statistically significant differences between the genders were found ( $p>0.05$ ). No statistically significant differences on HAD anxiety or depression were found between patients with whiplash injuries and patients with other causes to their trauma. A statistically significant correlation was found between post-traumatic stress on the total IES scores and anxiety on the HAD scores $(r=0.225$, $p=0.005$ ), but not between post-traumatic stress and depression. Participants with moderate to severe stress reaction (IES score $>26$ ) reported statistically significant higher anxiety scores on the HAD $(p=0.030)$ in comparison with patients with mild stress (IES score $<26$ ) (Figure 2).

\section{Pain intensity}

Pain intensity on the VAS for all subjects was $61.5 \pm 21.3 \mathrm{~mm}$. Women reported slightly higher scores $(62.9 \pm 19.6 \mathrm{~mm})$ than men $(58.9 \pm 24.0 \mathrm{~mm})$, but no significant difference $(\mathrm{p}>0.05)$ was found between genders. No statistically significant differences were found between patients with whiplash injuries and patients with other trauma ( $\mathrm{p}>0.05)$. Pain intensity on the VAS was significantly correlated to post-traumatic stress (total IES score) $(r=0.183, p=0.022)$, anxiety $(r=0.186$, $\mathrm{p}=0.0021)$ and depression $(\mathrm{r}=0.252, \mathrm{p}=0.002)$.

\section{Discussion}

This pilot study shows that the level of post-traumatic stress and pain intensity were high in the patients with a history of injury-related chronic pain. Possible depression or anxiety was reported by more than $40 \%$ of the participants. Pain intensity was correlated to post-traumatic stress, depression and anxiety and a significant relationship was found between post-traumatic stress and anxiety.

\section{Post-traumatic stress}

Post-traumatic stress reactions are described after traffic accidents and chronic whiplash patients in particular are expected to suffer from post-traumatic stress (Kuch et al 1996; Andersson et al 1997; Taylor et al 2001). In the present study, $48 \%$ of the participants suffered from moderate to severe stress which is classified as distinct stress response according to Kongsted and colleagues (2007) and a mild stress response was observed in $52 \%$, which is clearly higher than previous results reported in whiplash patients (mild stress 
Anxiety and post-traumatic stress

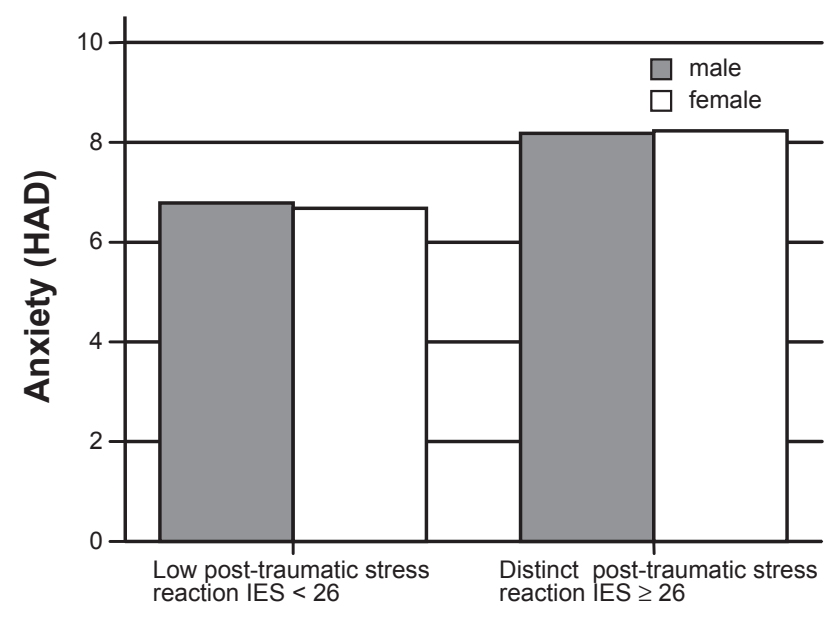

Figure 2 Anxiety in relation to stress response IES = impact of event score.

response in $87 \%$, distinct stress in $13 \%$ ) early after injury (within 10 days) (Kongsted et al 2007). Post-traumatic stress expressed as total IES score was also high in comparison with previous results of traffic victims with post-traumatic stress disorder late after injury (43.8 months) (Kuplich et al 2007). No difference, however, was found regarding post-traumatic stress scores between patients with whiplash injuries and patients with other injuries, a finding that might be explained by the underestimation of the rate of post-traumatic stress after injuries. Despite the fact that post-traumatic stress complaints often decrease over time after the injury, the post-traumatic stress levels in our study more than five years after the trauma were fairly high and seem to agree with Mayou and colleagues (2000) who found that about one-third of traffic victims still suffer from post-traumatic stress reactions with anxiety and avoidance behaviour up to six years after the accident.

\section{Anxiety and depression}

More than $40 \%$ of the participants fulfilled the criteria for possible/probable depression or anxiety disorder according to the HAD scores (Zigmond and Snaith 1983), which is clearly higher than previous studies have found in patients with whiplash injuries (Wenzel et al 2002). The anxiety scores were also much higher than in an uninjured Swedish population (Lisspers et al 1997) and slightly higher than in a previous study on chronic pain patients from our clinic (Branstrom and Fahlstrom 2008). Although women scored higher on HAD anxiety than men, the difference was not significant. In addition, there were no differences when comparing depression scores between men and women. Similarly, there was no statistically significant difference between patients with a whiplash injury and other injuries.

A previous study has correlated post-traumatic stress both with anxiety and depression in patients with chronic pain (Gayle Beck et al 2003). In the present study, this relationship was only shown between total post-traumatic score on the IES and HAD-anxiety. There is no clear reason for this result since the level of HAD-depression in our study was fairly high. However, we cannot rule out that the participant's personal characteristics might influence the results.

\section{Pain intensity}

In the present study, patients rated pain intensity on VAS. The mean scores were high in comparison with previous studies of whiplash patients (Berglund et al 2006; Bunketorp et al 2006). Although women reported higher scores than men, the difference was not significant. The mean VAS scores for all patients were slightly lower than previously reported by Becker and colleagues (2000) in a sample of patients with both injury and non-injury related chronic pain before treatment, however, the VAS scores were clearly higher than patients with strictly injury-related chronic pain who were referred to a pain rehabilitation programme (Roth et al 2008). Pain intensity was significantly related to post-traumatic stress as well as to depression and anxiety. These findings agree with a recently published study by Roth and colleagues (2008). They found that depressive symptoms directly influenced pain intensity and unresolved post-traumatic stress symptoms contributed to the level of depression and pain in patients with accident-related chronic pain. Relationships between pain, depression and post-traumatic stress symptoms have also been shown in some previous studies, and it has been proposed that in patients with chronic pain after accidents that these symptoms may co-exist and interact with each other (Bryant 2001; McCauley et al 2001).

These findings highlight the importance of considering the possible impact of post-traumatic stress, anxiety and depression on injury-related chronic pain patients.

\section{Disclosure}

The authors report no conflicts of interest in this work.

\section{References}

Andersson AL, Bunketorp O, Allebeck P. 1997. High rates of psychosocial complications after road traffic injuries. Injury, 28:539-43.

Barnsley L, Lord S, Bogduk N. 1994. Whiplash injury. Pain, 58:283-307. 
Becker N, Sjogren P, Bech P, et al. 2000. Treatment outcome of chronic non-malignant pain patients managed in a danish multidisciplinary pain centre compared to general practice: a randomised controlled trial. Pain, 84:203-11.

Berglund A, Bodin L, Jensen I, et al. 2006. The influence of prognostic factors on neck pain intensity, disability, anxiety and depression over a 2-year period in subjects with acute whiplash injury. Pain, 125:244-56.

Borg J, Gerdle B, Stibrant Sunnerhagen K. 2006. [Rehabiliteringsmedicin-bakgrund och aktuell roll i sjukvården.] In: Borg J, Gerdle B, Grimby G, et al. (eds). Rehabiliteringsmedicin Teori och Praktik, Denmark: Narayana Press, p. 17.

Branstrom H, Fahlstrom M. 2008. Kinesiophobia in patients with chronic musculoskeletal pain: Differences between men and women. J Rehabil Med, 40:375-80.

Bryant RA, Marosszeky JE, Crooks J, et al. 1999. Interaction of posttraumatic stress disorder and chronic pain following traumatic brain injury. J Head Trauma Rehabil, 14:588-94.

Bryant RA. 2001. Posttraumatic stress disorder and mild brain injury: controversies, causes and consequences. J Clin Exp Neuropsychol, 23:718-28.

Bunketorp L, Lindh M, Carlsson J, et al. 2006. The perception of pain and pain-related cognitions in subacute whiplash-associated disorders: its influence on prolonged disability. Disabil Rehabil, 28:271-9.

Carroll LJ, Cassidy JD, Cote P. 2006. Frequency, timing, and course of depressive symptomatology after whiplash. Spine, 31:E551-6.

Cote P, Cassidy JD, Carroll L, et al. 2001. A systematic review of the prognosis of acute whiplash and a new conceptual framework to synthesize the literature. Spine, 26:E445-58.

Gayle Beck J, Gudmundsdottir B, Shipherd JC. 2003. PTSD and emotional distress symptoms measured after a motor vehicle accident: Relationships with pain coping profiles. J Psychopathol Behav Assess, 25:219-27.

Hasselstrom J, Liu-Palmgren J, Rasjo-Wraak G. 2002. Prevalence of pain in general practice. Eur J Pain, 6:375-85.

Herrstrom P, Lannerbro-Geijer G, Hogstedt B. 2000. Whiplash injuries from car accidents in a Swedish middle-sized town during 1993-95. Scand $J$ Prim Health Care, 18:154-8.

Horowitz M, Wilner N, Alvarez W. 1979. Impact of Event Scale: a measure of subjective stress. Psychosom Med, 41:209-18.

[IASP] International Association for the Study of Pain. 1979. Pain terms: a list with definitions and notes on usage. Pain, 249-52.

Jaspers JP. 1998. Whiplash and post-traumatic stress disorder. Disabil Rehabil, 20:397-404.

Joseph S. 2000. Psychometric evaluation of Horowitz's Impact of Event Scale: a review. J Trauma Stress, 13:101-13.

Kongsted A, Bendix T, Qerama E, et al. 2007. Acute stress response and recovery after whiplash injuries. A one-year prospective study. Eur $J$ Pain, 12:455-63.

Kuch K, Cox BJ, Evans RJ. 1996. Posttraumatic stress disorder and motor vehicle accidents: a multidisciplinary overview. Can J Psychiatry, 41:429-34.

Kupchik M, Strous RD, Erez R, et al. 2007. Demographic and clinical characteristics of motor vehicle accident victims in the community general health outpatient clinic: a comparison of PTSD and non-PTSD subjects. Depress Anxiety, 24:244-50.
Kyhlback M, Thierfelder T, Soderlund A. 2002. Prognostic factors in whiplash-associated disorders. Int J Rehabil Res, 25:181-7.

Lisspers J, Nygren A, Soderman E. 1997. Hospital Anxiety and Depression Scale (HAD): some psychometric data for a Swedish sample. Acta Psychiatr Scand, 96:281-6.

Mantyselka P, Kumpusalo E, Ahonen R, et al. 2001. Pain as a reason to visit the doctor: a study in Finnish primary health care. Pain, $89: 175-80$.

Mayou RA, Black J, Bryant B. 2000. Unconsciousness, amnesia and psychiatric symptoms following road traffic accident injury. $\mathrm{Br} J$ Psychiatry, 177:540-5.

McCauley SR, Boake C, Levin HS, et al. 2001. Postconcussional disorder following mild to moderate traumatic brain injury: anxiety, depression, and social support as risk factors and comorbidities. J Clin Exp Neuropsychol, 23:792-808.

Price DD, Bush FM, Long S, et al. 1994. A comparison of pain measurement characteristics of mechanical visual analogue and simple numerical rating scales. Pain, 56:217-26.

Radanov BP, Sturzenegger M, Di Stefano G. 1995. Long-term outcome after whiplash injury. A 2-year follow-up considering features of injury mechanism and somatic, radiologic, and psychosocial findings. Medicine (Baltimore), 74:281-97.

Rodriquez AA, Barr KP, Burns SP. 2004. Whiplash: pathophysiology, diagnosis, treatment, and prognosis. Muscle Nerve, 29:768-81.

Roth RS, Geisser ME, Bates R. 2008. The relation of post-traumatic stress symptoms to depression and pain in patients with accident-related chronic pain. J Pain, 9:588-96.

Scrimshaw SV, Maher C. 2001. Responsiveness of visual analogue and McGill pain scale measures. J Manipulative Physiol Ther, 24:501-4.

Spitzer WO, Skovron ML, Salmi LR, et al. 1995. Scientific monograph of the Quebec Task Force on Whiplash-Associated Disorders: redefining "whiplash" and its management. Spine, 20:1S-73S.

Sterner Y, Toolanen G, Gerdle B, et al. 2003. The incidence of whiplash trauma and the effects of different factors on recovery. J Spinal Disord Tech, 16:195-9.

Sundin EC, Horowitz MJ. 2002. Impact of Event Scale: psychometric properties. Br J Psychiatry, 180:205-9.

Taylor S, Fedoroff IC, Koch WJ, et al. 2001. Posttraumatic stress disorder arising after road traffic collisions: patterns of response to cognitivebehavior therapy. J Consult Clin Psychol, 69:541-51.

[SCTA] The Swedish Council on Technology Assessment in Health Care. 2006. [Metoder för behandling av långvarig smärta.] Stockholm: Mölnlycke.

[SSM] The Swedish Society of Medicine and the Whiplash Commission task force. 2005. [Diagnostik och tidigt omhändertagande av whiplashskador.] Stockholm: Sandviken.

Wenzel HG, Haug TT, Mykletun A, et al. 2002. A population study of anxiety and depression among persons who report whiplash traumas. $J$ Psychosom Res, 53:831-35.

Wewers ME, Lowe NK. 1990. A critical review of visual analogue scales in the measurement of clinical phenomena. Res Nurs Health, 13:227-36.

Zigmond AS, Snaith RP. 1983. The hospital anxiety and depression scale. Acta Psychiatr Scand, 67:361-70. 
